\title{
Border Spaces: Geographies of Youth Exclusion, Inclusion, and Liminality
}

\author{
Bronwyn Wood
}

\section{Contents}

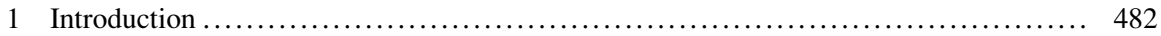

2 Studies of Young People, Space, and Exclusion ............................. 482

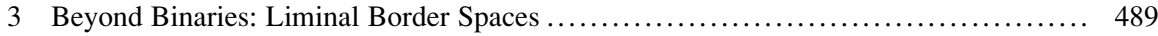

4 Liminality, Progressive Space, and Young People's Geographies of Exclusion ......... 490

5 Excluded Youth and Liminal Possibilities ..................................... 493

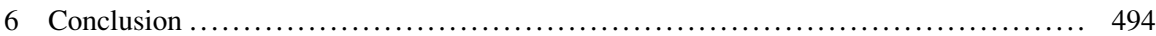

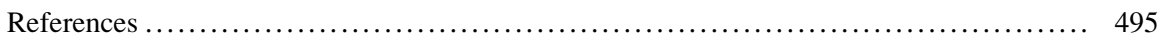

\begin{abstract}
A central focus in the work of children's geographies has been an analysis of children and young people's exclusion. This chapter reviews a number of these studies, classifying them into four broad approaches to exclusion. This typology illustrates a broadening of the focus and definition of "exclusion" and the introduction of related concepts such as inclusion and resistance. The second half of the chapter suggests we need to go further and take a more explicit focus on the in-between or liminal spaces between inclusion/exclusion of young people. Extending upon the original anthropological conceptualization, liminality is theorized as a concept that creates space for both political possibilities and hybrid identities for young people in "borderlands." Experiences of "marginal" youth in a semirural town in New Zealand are used to illustrate the potential of liminality in understanding the blurred inclusionary and exclusionary border spaces of youth.
\end{abstract}

\footnotetext{
B. Wood $(\bowtie)$

Faculty of Education, Victoria University of Wellington, Wellington, New Zealand e-mail: Bronwyn.wood@vuw.ac.nz
} 


\section{Keywords}

Exclusion • Inclusion • Liminality • Border youth • Citizenship • Participation

1 Introduction

A central focus in the subdiscipline of children's geographies has been an analysis of children and young people's exclusion in society (Vanderbeck and Dunkley 2004). Indeed, as Vanderbeck and Dunkley (2004) argue, the very development of children's geographies into a recognizable subfield "has in no small part been predicated on an exclusion of geographies i.e. the exclusion of young people's lives and experiences from the mainstream of human geography, mirroring the broader patterns of social relations which peripheralize young people's experiences and perspectives" (p. 178). In this chapter, a review of this research on youth exclusion within children's geographies is undertaken to consider what insights it gives into the nature, patterns, scale, mobility, and processes of children and young people in society. This analysis draws attention to the spatial, temporal, and social "border spaces" which young people occupy in society. As Aitken and Plows (2010, p. 327) suggest, young people are "always on, in, around, or going through a border of some kind." Such border experiences are frequently ones of exclusion, in which young people's status and spatial mobility are restricted and curtailed by social, economic, and political regulations and expectations. Young people carry borders with them, and those borders change over time and over space (Aitken and Plows 2010). Yet, as research shows, border living has also resulted in new forms of agency and social inclusion, demonstrating ways young people connect, belong, and make a difference at the same time as living on the edge (Bosco 2010).

The chapter begins with a review of research on youth exclusion with a particular focus on the work of children's geographers. A typology of four key approaches is developed, showing how approaches to youth exclusion have changed and expanded over time to bring in other concepts such as inclusion, liminality, and resistance, thus enriching our understandings. In the second half of the chapter, the concept of liminality is explored in greater depth, and consideration is given to the potential it holds for providing more nuanced and deeper understandings of the blended, in-between spaces of youth inclusion/exclusion. The chapter concludes with a case study of the experiences of young people from a failing school on the "wrong side of the tracks" in New Zealand as a way to illustrate the concepts of exclusion, inclusion, and liminality in greater depth and consider new spaces of possibility for border youth.

\section{Studies of Young People, Space, and Exclusion}

Geographers have long held an interest in the patterns and processes of exclusion in society, pointing out that space and place are central components of the processes of exclusion (Aitken 2001; Massey 1995; Sibley 1995; Vanderbeck and Dunkley 2004). 
Table 1 Four approaches to youth exclusion

\begin{tabular}{l|l|l}
\hline $\begin{array}{l}\text { Approach to } \\
\text { exclusion }\end{array}$ & Description & Understanding of exclusion \\
\hline $\begin{array}{l}\text { Exclusion } \\
\text { through } \\
\text { regulation }\end{array}$ & $\begin{array}{l}\text { Youth experience social and spatial } \\
\text { exclusion, occupy different spatial } \\
\text { zones, and/or have constrained } \\
\text { access to public space due to } \\
\text { regulations, policies and rules }\end{array}$ & $\begin{array}{l}\text { Youth exclusion is largely a result } \\
\text { of adult regulation, attitudes, and } \\
\text { actions }\end{array}$ \\
\hline $\begin{array}{l}\text { Exclusion } \\
\text { through stigma } \\
\text { and } \\
\text { discrimination }\end{array}$ & $\begin{array}{l}\text { Youth exclusion is not only material } \\
\text { but also symbolic - as a result of } \\
\text { stigma, stereotypes, and } \\
\text { discrimination often based on class, } \\
\text { gender, race, sexuality, and disability }\end{array}$ & $\begin{array}{l}\text { Exclusion has affective and } \\
\text { symbolic dimensions that can also } \\
\text { reinforce spatial divides. Moral } \\
\text { and symbolic evaluations } \\
\text { contribute to discriminatory and } \\
\text { exclusionary practices }\end{array}$ \\
\hline $\begin{array}{l}\text { Youth resistance } \\
\text { to exclusion }\end{array}$ & $\begin{array}{l}\text { Young people resist adult } \\
\text { impositions and carve out spaces for } \\
\text { their existence }\end{array}$ & $\begin{array}{l}\text { Young people do not respond to } \\
\text { exclusionary practices and } \\
\text { processes passively. Instead, } \\
\text { young people show agency within } \\
\text { their constrained environments }\end{array}$ \\
\hline $\begin{array}{l}\text { Exclusion is } \\
\text { closely linked to } \\
\text { inclusion }\end{array}$ & $\begin{array}{l}\text { The processes and practices of } \\
\text { inclusion also imply exclusionary } \\
\text { actions and attitudes - boundary } \\
\text { setting of how is/is not "one of us" }\end{array}$ & $\begin{array}{l}\text { Exclusion and inclusion are } \\
\text { interconnected, and one needs to } \\
\text { be understood in the context of the } \\
\text { other }\end{array}$ \\
\hline
\end{tabular}

A focus on "social exclusion" as a prominent feature of academic and social policy discourses in Western nations over the past decades has also reinforced interest in this concept (Vanderbeck and Dunkley 2004). The flexibility of the term "exclusion" is perhaps one of its greatest appeals, as it can be used to describe the economy and labor market, but also broadly varying dimensions of social difference, including "race," ethnicity, social class, gender, sexuality, and disability (Vanderbeck and Dunkley 2004). The following section outlines four of the key ways that geographers of children and young people have researched and understood exclusion and to what effect. These four approaches are not intended to be distinct from each other - in fact, some of the research discussed features across more than one category. Instead, the intention of this typology is to demonstrate some of the key traditions in the study of youth exclusion and how they have changed and broadened over time, enhancing our understandings and definitions of exclusion (and related concepts). A table summarizing these four approaches follows this discussion (Table 1).

Exclusion through regulation: A key contribution that children's geographers have made to studies of youth exclusion has been to show that young people occupy distinctive and frequently more restricted spaces in society compared to those of adults (Hil and Bessant 1999; Matthews et al. 1998; Skelton and Valentine 1998). Such research has confirmed that the mobility and experiences of young people are frequently confined to specific spatial arenas (Hall et al. 1999; Matthews et al. 1998). As such, young people inhabit "micro-geographies" (Matthews et al. 1998) or "micro-territories" (Harris and Wyn 2009) which are constrained spatially compared to those of adults. Research in this vein frequently portrays 
urban environments as sites of alienation, contestation, contamination, and surveillance in the "no go adult zones of the fortress city," creating "landscapes of powerlessness" and social marginality (Hil and Bessant 1999; Matthews et al. 1998; White 1996).

The above research reinforces how youth exclusion can be seen, at least in part, to be a result of adult regulation, processes, and practices, including laws, surveillance, and environmental planning. An extreme example of adult regulation of youth spatial mobility and access to public space is the use of age-based curfews (Collins and Kearns 2001; Manning et al. 2011; Skelton and Hamed 2011). For example, Collins and Kearns (2001) describe how a policy of age-based curfews of young people in two provincial towns in Aotearoa New Zealand - Te Kuiti and Paeroa - in the 1990s had the effect of significantly restricting young people's movements during the evening, especially those under 18 years. Both these towns had enforced a juvenile nighttime curfew over a period of 2 years in response to what was seen as wave of juvenile crime. These curfews also reinforced racial stereotypes of certain youth who were "trouble" and needed curtailment - specifically by targeting Māori or Pacific Island young people. Similar patterns of regulation and restriction of young people's mobility and actions were seen in age-related restrictions on young people's access of public space at night in Singapore in 2006 (Skelton and Hamed 2011). In contrast to Western notions of curfew, these restrictions were described as "police checks," and implemented on the premise of safety for teenagers and the promotion of greater parental responsibilities. Such policies can be seen as part of a wider raft of attempts aimed to enhance the control, regulation, and surveillance of young people (Manning et al. 2011).

Of significance in this approach to youth exclusion has been the examination of how adults' attitudes, anxieties, and suspicions toward young people have influenced young people's spatial constraints and exclusion. This confirms work by sociologists such as Cohen (1980) who describe the "moral panic" associated with youth and their use of public space (see also Hil and Bessant 1999; Lucas 1998). For example, Malone's (2002) research in Australia describes the way that suspicion, intolerance, and moral censure limit the spatial worlds of young urban youth in Australia. In Aotearoa New Zealand, Panelli and colleagues (2002) similarly profile the negative way young people are constructed in media to be "trouble." Their research showed how young people "hanging out" in public spaces was stigmatized with associations of drunkenness, lack of supervision, and disorder, suggesting that young people are out of place in public space, requiring adult supervision. Research in rural areas also confirms rural young people's experiences of exclusion and disadvantage. For example, the "hidden geographies" of exclusion and disenfranchisement in Northampton reveal a "darker" rural, where not all young people experience unfettered access to the countryside nor acceptance by adults in country towns (Matthews et al. 2000b). These findings critique the degree to which "public space" is indeed open to all members of the public.

Exclusion through stigma and discrimination: A second body of research moves beyond spatial and material types of youth exclusion and draws attention to more 
symbolic forms of exclusion, as a way to "connect the real (material geographies of place) with the imagined (symbolic geographies of space)" (Matthews et al. 2000a, p. 64). These forms of exclusion are far from imaginary - rather, they are much less visible and include more subtle forms of exclusion that are harder to see and measure, including emotional trauma experienced by groups which are considered abject or "out of place" in specific contexts (Sharkey and Shields 2008) or tainted with moral stigma as a result of class, gender, disability, or ethnicity (Holt 2004; Reay 2005; Reay and Lucey 2000; Skeggs 2004). Responses often include moral judgments and result in forms of discrimination, stigma, and stereotypes of children and young people who demonstrate "different" or "inferior" states to the dominant group. This research reveals that not only adults, but young people also conduct these types of exclusionary and discriminatory practices.

Research in this vein has explored how exclusionary practices and attitudes occur in response to aspects of class and moral "respectability" (Aitken 2001). Class-based identities are made and remade at the microlevel, in and through innumerable practices, serving to reproduce structural inequalities for children and young people and maintain levels of social exclusion (Reay 2005). Skeggs (2004) describes how through this process of class enactment, "entitlements and judgments of culture are put into effect and authorized" (p. 1009). For example, forms of discrimination relating to class in British schools constitute a "psychic landscape of class" through the feelings of ambivalence, inferiority and superiority, visceral aversions, recognition, abjection, and the markings of taste - which serve to reproduce and reinforce social class divisions (Reay 2005). Reay describes how children in her study did not necessarily mention class, but their talk was infused with class symbolism, class envy, and antagonism, through references to classrelated images associated with places (such as certain neighborhoods which were regarded as "posh" or working class). Such discussions have powerful emotional consequences for children and young people - such as feelings of anxiety and discomfort. Moreover, discriminating perceptions and practices can also lead to restrictions on children and young people's mobility, such as parental restrictions on children's access to inner-city council estates in Britain which are known as "hotbeds of crime" and "full of problem families" (Reay and Lucey 2000; see also Wridt 2004 for a similar case in Harlem, New York).

A key attribute of symbolic exclusion is how difficult exclusionary practices are to observe, even if it is felt deeply by those who experience it. Holt (2004) illustrates this clearly in her examination of the experiences of children with mind-body differences within a mainstream classroom. In spite of the attempts toward inclusion of these children with special educational needs (SEN) in the school, exclusionary processes operated which served to isolate and exclude them. This occurred in the dividing up of children in ways that clearly marked them out as "different" - such as the formation of set groups of ability and the separation of SEN children to a separate table to work with an assistant. These practices, while small, have the effect of separating off groups of children and young people, undermining perceptions of their equality and their ability to participate on the same level as "full" citizens (Sharkey and Shields 2008). 
A further significant aspect of symbolic exclusion relates to aspects of identity linked to race and ethnicity. Research in this area has identified that young people who are members of ethnic minority groups frequently experience forms of spatial and social exclusion (Cahill 2004; Hopkins 2004; Smith et al. 2002; Watt and Stenson 1998). For example, Watt and Stenson (1998) found that young people in South East England had markedly different patterns of spatial mobility according to perceived areas of "danger" associated with racialized perceptions of areas within "Thamestown." For example, Asian young people in this town kept to the "Asian area" of town but avoided other areas where they feared racial abuse or attacks. In contrast, the Afro-Caribbean young people did not feel unsafe anywhere in the town, and felt they could go anywhere. In both groups, "knowing people" was a key way to avoid trouble and enhance feelings of safety when using public space.

Being viewed with suspicion and disrespect as a result of ethnic identity is another way young people's participation in society can be restricted. For example, rural Māori young people from New Zealand described the abuse of their rights by schools, and police destroyed their trust in authorities and turned them off pursuing further opportunities to participate as citizens in their schools and communities (Smith et al. 2002). Exclusionary processes in these examples are difficult to measure but nonetheless lead to significant levels of discrimination as well as social and spatial marginalization of certain individuals and groups in society.

Youth resistance to exclusion: The final two approaches to youth exclusion research outlined in this chapter expand upon the first two by including additional, related concepts which add a new dimension to the study of youth exclusion. The third approach discussed here describes studies which have drawn attention to the way young people themselves respond to and resist exclusionary processes, impositions, and regulatory practices (Kallio and Häkli 2011b; Matthews 2003; Skelton and Hamed 2011; Smith 1998). Rather than depicting a rather passive portrayal of young people and exclusion, this approach highlights the agency of young people in defying adult-imposed constraints (Smith 1998) and their creativity in reshaping public space (Matthews 2003). While some forms of resistance to exclusion are public and obvious, such as youth street protests (Beals and Wood 2012; Tereshchenko 2010), others are more subtle, such as the occupation of a Kiikele Park in Oulu, Finland, by young people who had been locked out of this park, a favorite hangout, in the summer (Kallio and Häkli 2011b). Kallio and Häkli argue that the return of these young people to the park for weeks following the official closure of this park demonstrated their everyday embodied politics, in a form of everyday noncompliance, everyday "tactics" (de Certeau 1984), or, in their words, "voiceless politics."

This research underscores the ways that young people "operate their own spatialisations" (Jones 2000, p. 37) in the places they live, work, and go to school. For example, in Skelton and Hamed's (2011) research (referred to in the previous section), young people did not passively submit to the age-related restrictions to public space imposed on them by the police checks. Instead, they actively resisted these through tactics such as making themselves look more "adult" to avoid scrutiny or working to gain greater levels of trust from their parents in order to 
enhance their access to public space at nighttime. Resistance can also take the form of actively reclaiming spaces, such as the young people in East Germany both prior and post reunification who made use of abandoned buildings and subverted other spaces in order to find freedom and solidarity away from the gaze of the state (Smith 1998). Research itself can act as a form of resistance against exclusion, such as Cahill's (2004) Makes Me Mad project with diverse young women from the Lower East Side neighborhood of New York. Exclusion is seen in this type of research as something which young people can resist and work against - albeit in often subtle and everyday ways. This broadens our understandings by presenting new, agentic, and more inclusive ways of framing youth exclusion.

Exclusion is closely linked to inclusion: One final approach applied within studies of youth exclusion makes the point that processes of exclusion are inextricably tied to processes of inclusion. It is clear that both exclusionary and inclusionary practices structure young people's lived experiences of places (Nairn et al. 2003; Vanderbeck and Dunkley 2004). However, research on youth exclusion in this vein takes this a step further and suggests that inclusion and exclusion are not mutually defining opposites, but have a much more complex interrelationship (Cameron 2006). Researchers within this tradition have pointed to the simultaneity of inclusion and exclusion, and rather than studying inclusion or exclusion in isolation, both need to be explored together. Massey (1998) argues this from the starting point of understanding space in terms of a complexity of interacting social relations. She suggests that "it is important to recognise that within that open complexity [of interacting social relations], both individuals and social groups are constantly engaged in efforts to territorialise, to claim spaces, to include some and exclude others from particular areas" (Massey 1998, p. 126). As the following three examples illustrate, the formation of inclusion frequently occurs in close juxtaposition with the formation of exclusion (Hopkins 2004; Morris-Roberts 2004; Wridt 2004).

Processes of friendship inclusion necessarily employ exclusionary processes. Morris-Roberts (2004) illustrates this point in her analysis of girls' friendships in an English high school. She describes how a group of "alternative" girls collectively created a sense of "distinction" in their style, dress, and music tastes that reinforced their sense of belonging and identification as a group. She argues that these were also actions of "dis-identification" which served to form exclusionary boundaries from other girls, notably the "townies," who they saw as slaves to high street fashion, popular chart music, and forms of femininity found in teenage girls' magazines. In contrast the "alternative" girls distinguished themselves from the towny image of heteronormativity, by wearing grunge, punk, goth, or eclectic fashion and listening to indie and heavy metal music. Their actions were spatially reinforced by their use of distinct territories (such as the park or the school wall), which also served to demarcate their distinctiveness as a group of friends from the others. Morris-Roberts argues that the processes of becoming an "insider" also involved the creation of those who were "outsiders."

Similar processes also occur at wider scales in society. Wridt's (2004) work on "block politics" in East Harlem, New York, illustrates similar processes of 
inclusion/exclusion on a broader scale. She describes how the spatial unit of the "block" provided a sense of belonging, familiarity, and attachment, closely defining the identities of young people growing up there. This feeling of block attachment was validated and reinforced most acutely when young people enter other people's blocks as this was when distinctions between those in the "in-group" and those in the "out-group" were suddenly apparent. Her research also highlighted the close interaction of inclusion/exclusion with social status, spatial signifiers, and racial identities, describing how young people's identities were ascribed a certain status according to whether their block was considered "bad" or "tough."

With another scale in mind, Hopkins (2004) details the close relationship between inclusion and exclusion for young Muslim men growing up in Scotland. The claims of these young men to Scottishness (their accents, education, and commitment to Scotland) were juggled in tension with the marginalization they experienced through lack of access to employment and everyday racism as a result of their skin color or beards. Inclusion for these young Muslim men was formed on the borders of exclusion, depending largely on the degree to which they displayed their Muslimness. These three research examples illustrate how processes of exclusion and inclusion can be a form of "normative boundary setting" (Cameron 2006, p. 401) or as a way of distinguishing what is perceived as normality and morality from difference and immorality (Cameron 2006).

So, what have these four approaches told us about young people, space, and exclusion? Table 1 provides a summary of these four key approaches to youth exclusion, once again bearing in mind productive overlaps between each approach.

This collective work has underscored that young people are subject to high levels of adult regulation in various forms that have the effect of curtailing or manipulating their experiences of space. It is apparent, however, that young people employ a variety of strategies and "tactics" (de Certeau 1984) to subvert and resist adult impositions, to carve out spaces of their own both within and beyond these constraints. These approaches have also drawn attention to a much wider definition of exclusion - including not only spatial exclusion but forms of social and psychological exclusion which often have a deeply affective component. Forms of exclusion therefore include discriminatory practices and processes which often result in stigmatization and marginalization of those who are viewed as "other," reinforcing structural and identity-related divisions of gender, class, race, and disability. Importantly, this body of research has also drawn into sharp relief processes of inclusion. As Vanderbeck and Dunkley (2004) state, "this exclusion narrative, [...] is tempered with a recognition that exclusion is certainly not the only reality of young people's experiences" (p. 179). As many authors have shown, exclusion is necessarily understood in relation to inclusionary practices.

This loose typology of approaches to the study of youth exclusion also shows how understandings and definitions of exclusion have changed and broadened, furthering insights into the multiple dimensions and scales of exclusion (and related concepts such as inclusion, resistance, and agency), as well as deepening understandings of the spatial outcomes of exclusionary practices. These studies within children's geographies have also shed light on how exclusion is perceived, 
experienced, and practiced by children and young people themselves. As hinted at in the final approach (exclusion is closely linked to inclusion), an emerging body of research attempts to examine more rigorously the interrelationship between inclusion and exclusion. Further research is needed which moves beyond the static binaries of either included/excluded in order to disrupt these dualisms (Nairn et al. 2003) and interrogates the middling, fuzzy border space of ambiguity positioned between these two positions more closely. In the following section, the idea of liminality is introduced as a starting point for a more explicit focus on the state of in-betweenness which young people experience. A case is made for the significance of "border" spaces, as ones which offer opportunities for both political possibility and hybrid identities.

\section{$3 \quad$ Beyond Binaries: Liminal Border Spaces}

The idea of liminality, literally meaning on the threshold, stems from Arnold van Gennep (1909) and Victor Turner's $(1967,1969)$ anthropological research. Originally coined by van Gennep, the word "liminal" is derived from the Latin words limen (threshold) and limes ("boundary," "frontier") and was originally applied to describe the quality of transition of rites of passage (such as birth, puberty, marriage) (van Gennep 1909). In the 1960s, Victor Turner rediscovered the importance of liminality as a way to explain the phases of transition in which people are "betwixt and between all the recognized fixed points in space-time of structural classification" (Turner 1967, p. 97). This understanding opens up space for possible uses of the concept beyond that of social rites of passage. Thomassen (2009) suggests that liminality is therefore applicable to both time and space:

Liminal places can be specific thresholds; they can also be more extended areas, like 'borderlands' or, arguably, whole countries, placed in important in-between positions between larger civilizations. Liminality can also be applied to larger groups (cohorts or villages), or whole societies, or even civilizations. (Thomassen 2009, p. 16)

Thomassen (2009) lays out three dimensions of liminality which he states relate to subjects (individuals, groups, and whole societies), temporality (moments, periods, and epochs), and spatiality (specific places, such as thresholds, as well as areas, zones and regions, or countries). This broad conceptualization of liminality opens up new potential for the use of liminality within studies of youth and exclusion and helps to interrogate the idea of "border" living.

A small number of studies have applied the notion of liminality to highlight the space that young people occupy in society, "positioned on a boundary or threshold" (Weller 2006, p. 102) and therefore one of in-betweenness (Beals and Wood 2012; Bucholtz 2002; Kallio 2007; Luzzatto and Jacobson 2001; Skelton 2000, 2010; Weller 2006, 2007; Wood 2012). Liminality, in this sense, exposes how young people's temporal stage in their life course (age) and status in society renders them neither completely "child" nor completely "adult," in their ability to operate as 
autonomous political agents or access the full entitlements of adult citizenship. This liminal space is characterized by uncertainty, in-betweenness, and ambiguity (Kallio 2007; Matthews 2003; Sibley 1995; Weller 2006), and as Skelton (2000) suggests, those in ambiguous positions are often marginalized in society.

These studies have broadly introduced the concept of liminality to youth studies; however, they have rarely considered how liminality might offer specific insights into the area of youth exclusion (cf. Skelton 2000). Liminality is related to exclusion in that it describes being in-between "separation" and "incorporation" (Balduk 2008). Liminality therefore presents an opportunity to interrogate the more ambiguous states of exclusion - such as a state that is "not completely" excluded, or a state at the intersection of inclusion/exclusion and one that requires further investigation at these very borders of coexistence. This concept also has the potential to highlight the material spaces of liminality that young people occupy and their temporal dimensions relating to age, moments, and generations (Andres and Wyn 2010). A focus on liminality therefore draws attention to the dynamic, unfolding, and often contradictory status of young people who are "betwixt and between the positions assigned and arrayed by law, custom, convention, and ceremonial” (Turner 1967, p. 95).

\section{$4 \quad$ Liminality, Progressive Space, and Young People's Geographies of Exclusion}

This section provides an outline of the possibilities offered by liminality as a concept to enhance studies and of young people's geographies. At the outset, it is important to be clear that liminality is a concept not a theory, and deeper theorizing of this within youth studies is still needed. Theorizing liminality, for example, through Bourdieu's notion of symbolic capital will add greater depth. An example of this is Skegg's (2004) work on class interests. She points out that Bourdieu's concept of class has a considerable degree of ambiguity. Rather than a static state, the middle class is historically variable and has frontiers which continue to be produced and transformed through struggle:

\footnotetext{
It is in these intermediate zones of social space that the indeterminacy and the fuzziness of the relationships between practices and positions are the greatest, and that the room left open for symbolic strategies designed to jam the relationship is the largest. (Bourdieu 1987, p. 12 cited in Skeggs 2004, p. 5)
}

Skeggs concludes that analysis of class should therefore aim to capture the ambiguity produced through struggle and fuzzy boundaries, rather than fix it in place in order to measure what we know (Skeggs 2004, p. 5). While the word ambiguity does not equate to liminality, Skeggs nonetheless presents a much more nuanced and complex understanding of class-related spaces, which could well be described as liminal as opposed to fixed. A similar goal is intended through the application of liminality in the context of youth exclusion. While this chapter does not employ a specific theoretical lens with liminality, encouragement of doing so is implicit. 
Broadly, there are three main contributions that a more explicit recognition of liminality could offer. First, a focus on liminality draws attention to uncertainty and ambiguity. This highlights the fluidity, the moments, or space that exist "betwixt and between all the recognised fixed points in space-time of structural classification" (Turner 1967, p. 97) rather than fixed points of certain and rigidity. Balduk (2008) suggests that liminal phases are therefore in between "separation" and "incorporation" and therefore are closely related to exclusion or at least seclusion. Liminality therefore is a particularly useful concept for exploring youth, as a reflection on their state of ambiguity in society - the not-quite-adult status, or their "incongruous, extraneous position 'outside' but within society" (Sharkey and Shields 2008, p. 252). Furthermore, following feminist and poststructural approaches, liminality offers an opportunity to deconstruct dichotomies and binaries that often see one state in opposition to another (such as rural/urban, male/ female, public/private, and so on) (Nairn et al. 2003).

A second contribution of the concept of liminality in youth geographies is the potential it offers for a greater understanding of material space. While van Gennep (1909) and Turner (1967) applied the notion of liminality to rituals such as birth, puberty, and marriage, a great deal of potential remains to explore the spatiality of liminality more closely, by drawing attention to the material and symbolic geographies of space associated with spaces that can be seen to exist on a spatial frontier, border, or threshold (Thomassen 2009). In particular, it draws attention to spaces which could be considered marginal, excluded, on the borders of society, or beyond dominant patterns of practice. For example, Matthews (2003) describes "the street" liminal as such sites are simultaneously spaces of adult regulation, socialization, and control, yet also sites of youthful agency, subversion, and resistance (Matthews 2003). Similarly, Wood (2012) outlines how school playgrounds, classrooms, or toilets can also be analyzed as liminal spaces as they exist simultaneously as arenas of adult regulation, yet also of youth negotiation, subversion, and agency. Such sites could not be considered as entirely "adult" spaces, nor entirely "youth" spaces, but operate as something "in-between."

Third, liminality provides potential to consider the complex states of in-betweenness and to read these as spaces of political possibility. This is in spite of Turner's (1969) understanding of agency as a key dimension of liminality. He explains that the concept of liminality:

served not only to identify the importance of in-between periods, but also to understand the human reactions to liminal experiences: the way liminality shaped personality, the sudden foregrounding of agency, and the sometimes dramatic tying together of thought and experience. (p. 14)

Viewing the potential for agency within liminality offers a chance to advance the rather intractable debates about structure versus agency that lurch from one side to the other. Instead, an opportunity presents itself for a much greater analysis of the "middling position" (Farrugia 2012; Threadgold 2011) that most of these debates end with. Liminality focuses attention not on either structure or agency but the 
fuzzy state of ambiguity that might sit in between these positions. In particular, it offers an opportunity to consider the intersection of young people's and adults' worlds, rather than seeing these as separate (Jeffrey 2011; Mannion 2007). It also encourages researchers to consider the agency of social actors present within such liminal spaces and statuses, as a state of in-betweenness that has political potential.

One example of such an approach is Skelton's (2010, p. 150) appeal to the possibility and multiplicity which could exist at the intersection (in the "/" space) between Politics/politics. Drawing a distinction between "Politics" and "politics," Skelton argues that the traditional focus on big "P" Politics has paid disproportionate attention to formal and public forms of participation, such as institutions and processes of the state, thus overlooking informal and personal "politics" (lowercase p), related to issues of identity, agency, and participation which are more commonly the domain of children and young people (Skelton 2010). She suggests that young people's legal-political in-betweenness, their liminality, enables them to occupy two Political/political spaces at the same time, thus producing "a melded and blended P/politics."

Furthering Skelton's attention to this interstitial space through empirical work with school-aged young people, Wood (2012) suggests that examining the ambiguous and contradictory nature of liminal spaces within schools, in between formal/ informal and public/private arenas, provides fresh political possibility. Such spaces are highly regulated, yet also sites where young people negotiate adult rules and develop their own in ways that bind young people's and adult's political and social worlds together (Kallio and Häkli 2011a; Mannion 2007). Young people's very knowledge of liminal spaces and experiences of living within such blurred boundaries can enable new forms of politics to emerge within the blurred spaces, betwixt and between adults' and young people's worlds, in experiences of, for example, bullying or environmental waste (for examples, see Wood 2012).

Experiences of liminality therefore may not be entirely negative or powerless. As border dwellers, young people can recognize the powerlessness of others and also develop effective tactics that match the context in ways that adults cannot. This also reflects young people's own experience of hybridity and moving between child/youth and adult worlds with agility as "edge walkers" (Tupuola 2004). Tupuola (2004, drawing on Kreb 1999), in reference to diasporic Pacific Island youth in Australia and New Zealand, advances the idea of an edge walker as a minority youth who is resilient to cultural shifts and able to maintain continuity "wherever he or she goes, walking the edge between... cultures in the same persona" (Krebs 1999, p. 9). Rather than seeing the position of multiple identities as deficit, the concept of edge walkers infuses such identities with resilience and strength, showing the ability to juggle multiple social contexts and identities with agility. While this vision overlooks some of the very real difficulties facing minority youth, it highlights the potential agency of such young people within their marginalization. Liminality similarly speaks to a position of not only marginalization but also power, "derived from the margins that to some extent fosters anger and a sensibility that enables creativity and inventiveness" (Aitken 2004, p. 172). 


\section{$5 \quad$ Excluded Youth and Liminal Possibilities}

So what could an application of liminality look like when examining a group of "excluded" young people? In the following, such an approach is taken with a group of semirural New Zealand young people, who were located on the "wrong side of the tracks" in a provincial town in New Zealand. They attended a school, "Koru" College (pseudonyms for all participants and the school have been used), which in recent years had diminished in number, forcing the Board of Trustees to make a decision to close the school with less than 220 students in 2008. This planned closure and merger with the "successful" school on the other side of the tracks (West Side High) had not gone ahead as West Side High had declined the offer to merge and there was a concerted effort by community members to keep the school afloat. My research in the school came about in 2013 with an invitation to develop a participatory PhotoVoice project as part of the school curriculum with the aim of "celebrating the strengths in the community" (Wood 2015).

A key motivation for the project was the nature of youth exclusion and marginalization in this town, closely associated with this "failing" school. Even though the school had regained students and was slowly growing 5 years on, it still suffered from "perception problems" and ongoing stigma which a local newspaper claimed was associated with the lower socioeconomic status and high Māori population of residents in the community directly surrounding the school. It was apparent that patterns of exclusion were spatially, socially, and historically inscribed within this town. The location of Koru College near to a large state housing block, developed in the 1960s, was one of the reasons for ongoing narratives of failure in the town. For example, commonly reported perceptions of the school at the time of its planned closure in 2008 were:

\footnotetext{
[Koru College] was built in the 'wrong place'. [Koru College] is at the edge of town and on the unfavoured East side. [Koru College] has suffered from the socio-economic, racist and snobbish attitudes that have developed in [town] about the so called East/West divide;

[Koru College] is the 'appropriate' school in [town] for difficult students and for Māori students. (School media archives, 2008)
}

The spatial perceptions were heightened by the presence of a school zone demarcation which ran through the center of this town, dividing the wealthier west side from Koru College on the east, excluding the young people from this side of town from enrolling. This, along with the place images associated with the state housing block, created an uneven "power geometry" within this town (Massey 1995), isolating one community from the "other," reducing social interactions and tainting the excluded with stigma and forcing them to the periphery (Goffman 1963). These power geometries of exclusion were also sedimented through metaphorical and symbolic associations of place with moral judgments on the residents and their character. Teachers described how their (mainly Māori) students were often viewed with fear and suspicion in the town and faced significant barriers when accessing health and social care. One teacher, Anna, stated "our students have to be 
doubly good to succeed," explaining that they had to overcome initial prejudices of failure and then succeed to a degree that others would believe they were indeed capable. These examples highlight the continuing salience of race and class as a marker of social difference and otherness and the exclusionary processes which restricted these young people from full participation in this regional town.

However, in contrast to the rather spatially and historically deterministic pattern of "failure" associated with Koru College, young people did not have strong feelings of aversion to their school or their side of town. Instead, their experiences represented a tangled state of inclusion/exclusion. While only about one quarter of the participants lived in the much-reviled state housing block near Koru College, most were very familiar with it as they walked through the area regularly or had friends there. On our community walks through this block, young people would often call out to family and friends, or an "aunty" would poke her head out and ask what we were doing. This enhanced the young people's sense of security and safety as they walked about the block as they were always "known" (Watt and Stenson 1998). For young people who did live there, it was not a site of contamination - it was just "where we live." Many also spoke positively of the pride they had in their local marae (Māori for traditional meeting house) and the identity this gave them; and others described how Koru College contributed to their identity on East Side.

While the picture of an excluded school community had initially been painted at the outset of the project, these young people were not defined by exclusion. In fact, there were times they described with pride, but also agency, that they had chosen to be part of the East Side community. Joanne (age 13) described how she had chosen the school over the West Side High School as "my sister had such a bad time there that my Mum said there was no way I would go there." This was even more apparent when during the year of research, West Side High removed its zone for the first time in 10 years allowing East Side young people to enroll (in response to its falling roll numbers reflecting rural population decline). Fears that this could further destabilize the low roll numbers at Koru College were short-lived; both students and staff laughed at the thought Koru College students were now wanted by West Side High: “We won't be going there. They don't understand us and how we do things the Koru College-way."

\section{Conclusion}

This chapter began by reviewing research on youth exclusion, demonstrating how other related concepts, such as inclusion, resistance, and agency, have become a strong feature of children's geography research. The typology of four approaches to youth exclusion provides a starting point for future research and has highlighted expanding and deepening understandings of youth exclusion in this field. In the second half of the chapter, a case has been made for more in-depth work around the in-between spaces at the intersection of inclusion/exclusion, with the concept of liminality highlighted as a key conceptual starting point. 
The final example of young people's experiences at Koru College illustrated how and why this approach might be operationalized. Aspects of all four approaches to exclusion outlined earlier can be seen in this example, showing how these young people were spatially and socially (symbolically) excluded, yet also demonstrating resistance and agency, also at the intersection of experiences of inclusion. Moreover, the nature of their exclusion was characterized by symbolic forms of judgment and stigma in response to the inclusive and exclusive processes of social relationships that focused on "people like us." Applying the idea of liminality to this context revealed how young people were neither completely excluded nor completely included in this town. Instead, they occupied a hybrid space, finding belonging and attachment in their community while simultaneously recognizing that their experience as citizens was peripheral to the dominant groups in town. As border youth, they found affiliation through their Māori identity and sense of belonging in their school community yet also expressed a sense of alienation from the dominant players on the "other" side of town (Wood 2015).

Yet, within this liminal position, young people also had a sense of agency and power to some extent. When the West Side High School finally removed its school's geographic zone and allowed these young people in, they subverted expectations that they would be clamoring to attend by reasserting their sense of connection to the East Side and Koru College which did things "their way." The ambiguity of their position, produced through struggle and fuzzy boundaries (Skeggs 2004, p. 5), reveals a far more complex narrative than simply inclusion or exclusion. As young people living on the borders of this town, they were walking on the edge between juxtaposing narratives of failure and success, belonging and exclusion, sometimes finding strength, agency, and resilience in that liminality and sometimes finding exclusion.

In sum, liminality offers a conceptual lens through which to interrogate the ambiguities and complexities of youth exclusion. This chapter has outlined a rationale for the application of liminality as a lens for scholarship on the "border spaces" of youth. The challenge remains to find research tools, methodologies, and theoretical frameworks that can deepen this concept and in doing so provide further critical insights into understandings of youth exclusion.

\section{References}

Aitken, S. (2001). Geographies of young people: The morally contested spaces of identity. London: Routledge.

Aitken, S. (2004). Editorial: From dismissals and disciplinary exclusions: From block politics to panic rooms. Children's Geographies, 2(2), 171-175.

Aitken, S., \& Plows, V. (2010). Overturning assumptions about young people, border spaces and revolutions. Children's Geographies, 8(4), 327-333. doi:10.1080/14733285.2010.510997.

Andres, L., \& Wyn, J. (2010). The making of a generation: The children of the 1970s in adulthood. Toronto: Toronto University Press.

Balduk, J. (2008). On liminality: Conceptualising in 'between-ness'. Masters thesis, Radboud University of Nijmegen, Nijmegen. 
Beals, F., \& Wood, B. E. (2012). Negotiating agency: Local youth activism in Aotearoa New Zealand. In K. Brison \& S. Dewey (Eds.), Super girls, gangstas, freeters, and xenomaniacs: Gender and modernity in global youth cultures (pp. 193-210). New York: Syracuse University Press.

Bosco, F. J. (2010). Play, work or activism? Broadening the connections between political and children's geographies. Children's Geographies, 8(4), 381-390. doi:10.1080/14733285.2010. 511003

Bucholtz, M. (2002). Youth and cultural practice. Annual Review of Anthropology, 31, 525-552.

Cahill, C. (2004). Defying gravity? Raising consciousness through collective research. Children's Geographies, 2(2), 273-286.

Cameron, A. (2006). Geographies of welfare and exclusion: Social inclusion and exception. Progress in Human Geography, 30(3), 396-404. doi:10.1191/0309132506ph614pr.

Cohen, S. (1980). Folk devils and moral panics: The creation of the Mods and the Rockers. New York: St Martin's Press.

Collins, D., \& Kearns, R. (2001). Under curfew and under siege? Legal geographies of young people. Geoforum, 32(3), 389-403.

de Certeau, M. (1984). The practice of everyday life (trans: Rendall, S.). Berkeley: University of California Press.

Farrugia, D. (2012). Young people and structural inequality: Beyond the middle ground. Journal of Youth Studies, 16(5), 679-693. doi:10.1080/13676261.2012.744817.

Goffman, E. (1963). Stigma: Notes on the management of spoiled identity. Englewood Cliffs: Prentice-Hall.

Hall, T., Coffey, A., \& Williamson, H. (1999). Self, space and place: Youth identities and citizenship. British Journal of Sociology of Education, 20(4), 501-513.

Harris, A., \& Wyn, J. (2009). Young people's politics and the micro-territories of the local. Australian Journal of Political Science, 44(2), 327-344.

Hil, R., \& Bessant, J. (1999). Spaced-out? Young people's agency, resistance and public space. Urban Policy and Research, 17(1), 41-49.

Holt, L. (2004). Children with mind-body differences; performing disability in the school classroom. Children's Geographies, 2(2), 219-236.

Hopkins, P. E. (2004). Young Muslim men in Scotland: Inclusions and exclusions. Children's Geographies, 2(2), 257-272. doi:10.1080/14733280410001720548.

Jeffrey, C. (2011). Geographies of children and youth II: Global youth agency. Progress in Human Geography. doi:10.1177/0309132510393316.

Jones, O. (2000). Melting geography: Purity, disorder, childhood and space. In S. Holloway \& G. Valentine (Eds.), Children's geographies: Playing, living (pp. 29-47). London: Routledge.

Kallio, K. P. (2007). Performative bodies, tactical agents and political selves: Rethinking the political geographies of childhood. Space and Polity, 11(2), 121-136.

Kallio, K. P., \& Häkli, J. (2011a). Tracing children's politics. Political Geography, 30, 99-109.

Kallio, K. P., \& Häkli, J. (2011b). Young people's voiceless struggle over urban space. GeoJournal, 76, 63-75.

Krebs, N. (1999). Edgewalkers: Defusing cultural boundaries of the new global frontier. Far Hills: New Horizon Press.

Lucas, T. (1998). Youth gangs and moral panics in Santa Cruz, California. In T. Skelton \& G. Valentine (Eds.), Cool places: Geographies of youth culture (pp. 145-160). London: Routledge.

Luzzatto, D., \& Jacobson, Y. (2001). Youth graffiti as an existential coping device: The case of Rabin's assassination. Journal of Youth Studies, 4(3), 351-365.

Malone, K. (2002). Street life; youth, culture and competing uses of public space. Environment and Urbanization, 14(2), 157-168.

Manning, R., Jago, R., \& Fionda, J. (2011). Socio-spatial experiences of young people under antisocial behaviour legislation in England and Wales. In L. Holt (Ed.), Geographies of children, youth and families: An international perspective (pp. 221-232). Oxon: Routledge. 
Mannion, G. (2007). Going spatial, going relational: Why 'listening to children' and children's participation needs reframing. Discourse: Studies in the Cultural Politics of Education, 28(3), 405-420.

Massey, D. (1995). Making spaces or, geography is political too. Soundings, l(Autumn), 193-208.

Massey, D. (1998). Spatial construction of youth cultures. In T. Skelton \& G. Valentine (Eds.), Cool places: Geographies of youth cultures (pp. 121-129). London: Routledge.

Matthews, H. (2003). The street as a liminal space: The barbed spaces of childhood. In P. H. Christensen \& M. O’Brien (Eds.), Children in the city: Home, neighbourhood and community (pp. 101-117). London: Routledge/Falmer.

Matthews, H., Limb, M., \& Percy-Smith, B. (1998). Changing worlds: The micro-geographies of young teenagers. Tijdschr Econ Soc Geogr, 89(2), 193-202.

Matthews, H., Limb, M., \& Taylor, M. (2000a). The 'street as thirdspace'. In S. Holloway \& G. Valentine (Eds.), Children's geographies: Playing, living, learning (pp. 63-79). Oxon: Routledge.

Matthews, H., Taylor, M., Sherwood, K., Tucker, F., \& Limb, M. (2000b). Growing-up in the countryside: Children and the rural idyll. Journal of Rural Studies, 16(2), 141-153.

Morris-Roberts, K. (2004). Girls' friendships, 'distinctive individuality' and socio-spatial practices of (dis)identification. Children's Geographies, 2(2), 237-255. doi:10.1080/ 14733280410001720539.

Nairn, K., Panelli, R., \& McCormack, J. (2003). Destabilizing dualisms: Young people's experiences of rural and urban environments. Childhood, 10(1), 9-42.

Panelli, R., Nairn, K., Atwool, N., \& McCormack, J. (2002). 'Hanging out:' Print media constructions of young people in 'public space'. Youth Studies Australia, 21(4), 38-48.

Reay, D. (2005). Beyond consciousness? The psychic landscape of social class. Sociology, 39(5), 911-928.

Reay, D., \& Lucey, H. (2000). 'I don't really like it here but I don't want to be anywhere else'; Children and inner city council estates. Antipode, 32(4), 410-428.

Sharkey, A., \& Shields, R. (2008). Abject citizenship - rethinking exclusion and inclusion: Participation, criminality and community at a small town youth centre. Children's Geographies, 6(3), 239-256.

Sibley, D. (1995). The geographies of exclusion. London: Routledge.

Skeggs, B. (2004). Class, self, culture. London: Routledge.

Skelton, T. (2000). 'Nothing to do, nowhere to go?': Teenage girls and 'public space' in the Rhondda Valleys, South Wales. In S. Holloway \& G. Valentine (Eds.), Children's geographies: Playing, living, learning (pp. 80-99). Oxon: Routledge.

Skelton, T. (2010). Taking young people as political actors seriously: Opening the borders of political geography. Area, 42(2), 145-151.

Skelton, T., \& Hamed, N. A. (2011). Adult anxieties versus young people's resistance: Negotiating access to public space in Singapore. In L. Holt (Ed.), Geographies of children, youth and families: An international perspective (pp. 203-220). Oxon: Routledge.

Skelton, T., \& Valentine, G. (1998). Cool places: Geographies of youth cultures. London: Routledge.

Smith, F. (1998). Between east and west: Sites of resistance in East German youth cultures. In T. Skelton \& G. Valentine (Eds.), Cool places: Geographies of youth cultures (pp. 290-303). London: Routledge.

Smith, L. T., Smith, G. H., Boler, M., Kempton, M., Ormond, A., Chueh, H. C., \& Waetford, R. (2002). 'Do you guys hate Aucklanders too?' Youth: Voicing difference from the rural heartland. Journal of Rural Studies, 18, 169-178.

Tereshchenko, A. (2010). Ukrainian youth and civic engagement: Unconventional participation in local spaces. Journal of Youth Studies, 13(5), 597-613.

Thomassen, B. (2009). The uses and meanings of liminality. International Political Anthropology, 2(1), 5-27. 
Threadgold, S. (2011). Should I pitch my tent in the middle ground? On 'middling tendency', Beck and inequality in youth sociology. Journal of Youth Studies, 14(4), 381-393.

Tupuola, A. M. (2004). Pasifika edgewalkers: Complicating the achieved identity status in youth research. Journal of Intercultural Studies, 25(1), 87-100.

Turner, V. (1967). The forest of symbols: Aspects of the Ndembu ritual. New York: Cornell University Press.

Turner, V. (1969). The ritual process: Structure and anti-structure. New York: de Gruyter.

Vanderbeck, R., \& Dunkley, C. M. (2004). Introduction: Geographies of exclusion, inclusion and belonging in young lives. Children's Geographies, 2(2), 177-183.

vanGannep, A. (1909). The rites of passage. Chicago: Chicago University Press.

Watt, P., \& Stenson, K. (1998). The street: 'It's a bit dodgy around there'. In T. Skelton \& G. Valentine (Eds.), Cool places; geographies of youth cultures (pp. 249-265). London: Routledge.

Weller, S. (2006). Situating (young) teenagers in geographies of children and youth. Children's Geographies, 4(1), 97-108.

Weller, S. (2007). Teenagers' citizenship: Experiences and education. Oxon: Routledge.

White, R. (1996). No go in the fortress city: Young people, inequality and space. Urban Policy and Research, 14(1), 37-50.

Wood, B. E. (2012). Crafted within liminal places: Young people's everyday politics. Political Geography, 31(6), 337-346. doi:10.1016/j.polgeo.2012.05.003.

Wood, B. E. (2015). Excluded citizens? Participatory research with young people from a 'failing' school community. Children's Geographies, 1-15. doi:10.1080/14733285.2015.1043515.

Wridt, P. (2004). Block politics. Children's Geographies, 2(2), 199-218. 